\title{
Models cognitius per a la creació i la innovació en gastronomia
}

\author{
David Casacuberta \\ UNIVERSITAT AUTÒNOMA DE BARCELONA \\ david.casacubertafauab.cat
}

ORCID. 0000-0001-7119-9342

Rebut: 28/04/2020

Acceptat: 01/09/2020

\section{RESUM}

A partir de la reflexió feta per Ferran Adrià i el seu equip d'El Bulli, aquest article explora de quina forma certs mecanismes, tècniques i procediments creatius entorn de l'anomenada «gastronomia d'avantguarda» poden analitzar-se des d'un model enactivista de la cognició per tal d'entendre la creativitat en la cuina i caracteritzar els processos d'innovació. També s'intentarà establir si alguns d'aquests processos són suficientment generals com per a reutilitzar-los en altres disciplines i afavorir així la nostra comprensió teòrica dels processos i mecanismes de creació i innovació. Presentem així aquells trets que són específics de la gastronomia com a procés creatiu per destriar aquells fenòmens que són prou genèrics com per considerarlos constituents de la gran família dels processos creatius. D'aquesta manera l'article cerca presentar noves perspectives per a entendre el fet genèric de crear versus la creació específica en processos gastronòmics.

Paraules clau: El Bulli, artificació, gastronomia d'avantguarda, models de creativitat, Ferran Adrià.

ABSTRACT. Cognitive Models for Gastronomic Creation and Innovation

Based on the reflections of super-chef Ferran Adrià and his team at el Bulli restaurant, this paper explores how certain creative mechanisms, techniques and procedures surrounding avant-garde gastronomy can be analysed from an enactivist model of cognition in order to: (1) understand creativity in the kitchen; (2) characterise culinary innovation processes; (3) establish whether some of these processes are general enough to be re-used in other fields and so broaden our theoretical understanding of the processes and mechanisms involved in creation and innovation. We present those features that are specific to gastronomy as a creative process to distinguish them from others that are generic enough to form part of a larger family of creative processes. The paper seeks to present new perspectives on both subject-specific and generic creation processes in haute cuisine.

Keywords: el Bulli, confection, avant-garde gastronomy, creativity models, Ferran Adrià.

\author{
SUMARI \\ Introducció \\ Breu història de l'estudi interdisciplinari de la cuina \\ Per què investigar la gastronomia. Mites i realitats \\ - Estètica dels sentits menors \\ - L'economia de la cuina molecular \\ Anàlisi enactivista dels processos creatius en gastronomia molecular \\ - Què és un model cognitiu enactivista? \\ Conclusions \\ Referències bibliogràfiques \\ Nota biogràfica
}


Autor per a correspondència / Corresponding author: David Casacuberta. Departament de Filosofia. Edifici B (Campus de la UAB) 08193 Bellaterra. Cerdanyola del Vallès (Espanya).

Citació suggerida / Suggested citation: Casacuberta, D. (2021). Models cognitius per a la creació i la innovació en gastronomia. Debats. Revista de cultura, poder i societat, 135(2), 69-80. DOI: http://doi.org/10.28939/iam.debats-135-2.5

\section{INTRODUCCIÓ}

Aquest article explora la «gastronomia d'avantguarda» des de la perspectiva de l'enactivisme per tal d'oferir una nova visió a l'hora de caracteritzar els processos d'innovació. També intenta establir si alguns d'aquests processos són suficientment generals com per a reutilitzar-los en altres disciplines i afavorir així la nostra comprensió teòrica dels processos i mecanismes de creació i innovació. La pràctica de la gastronomia creativa per part de Ferran Adrià a El Bulli i la posterior reflexió teòrica en el seu grup de recerca «El Bulli Lab» s'analitzen en aquest article com a estudi de cas en el qual basar les nostres propostes.

En la primera secció descriurem l'evolució de la gastronomia i l'estudi d'aquesta. La segona secció cerca argumentar la rellevància teòrica de la gastronomia com a objecte d'estudi filosòfic. En una tercera secció estudiarem El Bulli des d'una perspectiva enactivista. L'última secció analitza com les idees presentades poden ajudar a oferir noves perspectives als processos d'innovació i creativitat.

\section{BREU HISTÒRIA DE L'ESTUDI INTERDISCIPLINARI}

\section{DE LA CUINA}

La gastronomia té totes les credencials per a considerar-se pràcticament una ciència aplicada. La cuina es basa en la transformació d'una sèrie de productes mitjançant canvis físics i reaccions químiques específiques (Castells i Perelló, 2010; McGee, 1984; Myhrvold, 2011). Tanmateix, històricament han estat dos mons que s'han ignorat mútuament. La gastronomia es recolçava bàsicament en l'experiència prèvia recollida en receptes i tècniques resultades de l'experimentació directa, sense aplicar processos de revisió i contrastació científica ni incloure resultats científics establerts al repertori. Així, en cuina podem trobar tècniques centenàries que coincideixen amb models teòrics de la química i la física, així com creences establertes durant generacions que no resisteixen una recerca científica detallada (López-Alt, 2015).

Els primers intents de fer una «ciència de la cuina» van tenir lloc al segle XIX amb investigacions com les d'Appert, que descrivien mètodes per a preservar els aliments (Appert, 1810), o Accum, un químic interessat en verins i ciències forenses, autor del primer tractat de química a la cuina (Accum, 1821). Però, en particular, Savarin, amb l'obra The Physiology of Taste (Brillat-Savarin, 1828), va presentar el primer discurs sobre la gastronomia científica, en el qual intentava establir les bases fisiològiques dels sentits de l'olfacte i del gust i la química dels processos de transformació d'aliments.

Al segle $\mathrm{xx}$, el primer autor en fer una apassionada defensa de la relació entre la ciència i la gastronomia va ser el físic hongarès Nicholas Kurti, precursor de la tendència actual de fusionar tecnologia i gastronomia. Amb la famosa conferència pronunciada el 1969, «El físic a la cuina», va demostrar, entre d'altres qüestions, les possibilitats culinàries d'una màquina de buit i del microones.

Al mateix temps, la primera edició del llibre de Herbert Simon, The Sciences of the Artificial, publicat el 1969, 
significava el reconeixement de l'estatus científic del disseny. Les teories de Simon van motivar el desenvolupament de metodologies sistemàtiques que eren rellevants per a moltes disciplines relacionades estrictament amb el disseny, com ara l'arquitectura, l'enginyeria, la planificació urbana, la medicina, la informàtica i la gestió.

Seguint les idees que Dorst (2006) i Cross (2007) van desenvolupar per parlar de disseny, podríem dir que la gastronomia és un espai per a treballar de manera dissenyada (designerly), on els problemes que el cuiner ha de resoldre no estan definits de manera perfecta, sinó que a mesura que el cuiner intenta respondre al problema, el problema en sí va canviant i evolucionant, en un procés complex de feedback. Tanmateix, fins entrat el segle xxi no hi ha cap intent rellevant d'analitzar la gastronomia des de les propostes de les ciències de disseny.

A la dècada dels vuitanta, l'enciclopèdia sobre menjar i cuina de Harold McGee (McGee, 1984) va impulsar el diàleg entre les ciències i la cuina, amb la qual cosa va construir un paradigma amb el qual cuinar seguint el mètode científic. Va introduir així una nova manera de considerar la cuina com un sistema teòric basat en coneixements científics sòlids: la gastronomia molecular, un terme concebut per Hervé This juntament amb l'esmentat Kurti (This, 2002; Kurti, 1980). Un altre text clau és la Guia científica $i$ gastronòmica (Fundación Alícia i elBullitaller, 2006) que tracta de dur a terme la primera classificació científica dels productes alimentaris utilitzats a la gastronomia.

Tanmateix, aquestes propostes tendien a donar un protagonisme excessiu a la ciència i convertien la cuina en gairebé una branca de la enginyeria, ja que oblidaven l'aspecte creatiu: la qüestió del wicked problem que indicàvem un parell de paràgrafs més amunt, quan citàvem Nigel Cross.

Nathan Myhrvold, per a tractar de trobar un equilibri entre la creativitat científica i l'artística d'aquest nou mètode de cuina, va decidir anomenar aquesta nova tendència "cuina modernista» $\mathrm{i}$ va dedicar sis volums a una investigació sistemàtica dels efectes de diferents tècniques i tecnologies en els aliments (Myhrvold, 2011), sense oblidar fer justícia també als aspectes creatius i no deterministes. A Espanya, Pau Arenós va buscar l'any 1999 un balanç similar i va encunyar el terme «cuina tecnoemocional» (Arenós i Jardí, 1999) per a capturar la barreja d'inspiració artística i mètode científic.

Els dos termes estàndard que s'usen per a referir-se a aquest nou paradigma — «gastronomia molecular» i «cuina tecnoemocional»—-tenen els seus punts forts i les seves limitacions a l'hora d'entendre la cuina. «Gastronomia molecular» mostra molt bé el vessant científic darrere d'aquesta disciplina i assenyala la química com la ciència clau de fons, però pot fer pensar erròniament que es tracta només de descobrir noves reaccions químiques per transformar la textura dels aliments.

«Cuina tecnoemocional» assenyala el fet que no es tracta d'aclaparar el client amb dades científiques abstruses, sinó de sorprendre, de crear noves emocions, de mostrar menjar en formes que mai hauria imaginat. Com Ferran Adrià comentava en parlar de la seva primera època en El Bulli, es tracta de «violar el paladar» del comensal (Adrià, 1998). «Tecno» apunta sens dubte a la necessitat de nous aparells, tècniques i tecnologies. No obstant això, fàcilment porta el no versat en la matèria a pensar simplement en frívols sistemes tecnològics per a presentar plats de la forma més rara possible.

Les ciències sensorials són una altra disciplina rellevant a l'hora d'analitzar la gastronomia des de les ciències del disseny. La psicologia de la percepció o la fisiologia humana són tan rellevants per a la gastronomia com per al disseny (Korsmeyer, 2002; Lyman, 2012). Considerem per exemple el concepte d'«aparellament d'aliments» (foodpairing). Es tracta d'una investigació que combina l'anàlisi estadística i la ciència cognitiva per tal de definir una metodologia per a establir quins aliments combinen bé i quins no, intentant anar més enllà d'aquelles combinaci- 
ons que han funcionat històricament. Un exemple clar d'aquesta recerca és el projecte «Foodpairing» (Robberechts et al., 2015), una empresa de tecnologia alimentària a l'avantguarda de la gastronomia, la ciència computacional i la publicitat digital. També tenim el projecte liderat per Barabasi d'establir foodpairings analitzant la presència comuna d'ingredients a receptes (Ahn et al., 2011).

\section{PER QUÈ INVESTIGAR LA GASTRONOMIA.}

\section{MITES I REALITATS}

És difícil trobar una disciplina més ignorada a les ciències i les humanitats que la gastronomia. Quan s'examina des de l'estètica i altres branques de la filosofia, normalment es fa amb displicència i atac directe. Només cal recordar el tracte pejoratiu que Plató dedica a cuiners i camperols a La República. Per a Plató, menjar és com una mena de mal necessari, i com menys en parlem millor.

Aquest fet és molt sorprenent, ja que contrasta radicalment amb la quotidianitat de menjar i de cuinar, així com amb l'interès general per l'experiència gastronòmica.

Aquesta ignorància i displicència es justifiquen amb una sèrie de prejudicis que en realitat no se sostenen.

\section{Estètica dels sentits menors}

Tenim primer la idea que el gust és un sentit pobre i irrellevant per a un estudi de la condició humana. Segons aquest prejudici, el gust seria un sentit primordial, animal, massa bàsic per a tenir la menor rellevància epistèmica o estètica; la mera juxtaposició de «salat», «dolç», «amarg» $\mathbf{i}$ «àcid» no permet construir cap model teòric conceptualment rellevant.

Tanmateix aquesta visió és en realitat una profecia autocomplerta. L'obsessió platònica de centrar-se en el món pur del pensament i evitar el cos és la responsable que no tinguem un vocabulari rellevant per descriure amb detall l'experiència fenomènica del gust i la seva capacitat de significació.
La nostra cultura no té gaire credibilitat a l'hora de teoritzar sobre el gust si considerem que cal esperar al segle xx per a la presentació del terme «umami» per referir-nos a un nou gust, associat a detectar la presència de proteïnes i substàncies com el glutamat monosòdic. En visió, això equivaldria a que cap crític d'art o teòric de la visió no hagués parlat mai del color violeta fins al segle xx. Hem d'esperar que arribe l'any 2010 per a confirmar quelcom que tots sabíem ja experiencialment: el greix és un sabor (Stewart et al., 2010; Keats i Constanzo, 2015). I hem d'esperar al segle xxi perquè comencin a sorgir teories competents que intentin explicar com funciona el sentit de l'olfacte, que és eminentment més complex que suposar que tenim al nas receptors per a cada molècula tipus (Hawkes i Doty, 2009).

\section{L'economia de la cuina molecular}

Un obstacle menor, més actual, però que també té pes a l'hora d'eliminar la gastronomia com a tema rellevant en les humanitats, és la caracterització de la gastronomia d'avantguarda com quelcom elitista, que tindria sobre tot una funció de capital social, de mostrar que un pertany a una classe benestant. Ser vist entrant en un restaurant catalogat amb tres estrelles a la Guia Michelin, descriure el menú experimental que un va fruir o anomenar els chefs pel nom de pila com si fossin grans amics és una forma de capital social en què es cerca sobre tot mostrar que a un li sobren els diners (Eloire, 2018).

L'eina principal d'aquest mecanisme de mostrar capital social seria la sobredimensió dels preus. La persona que visita un d'aquests restaurants d'avantguarda està pagant molt més del que costen els materials; l'accés és exclusiu i amb llarga espera. Així, el públic general no pot accedir a aquestes experiències perquè el preu és molt superior al cost real (Eloire, 2018).

Pel que fa a la sobredimensió cal dir que en línies generals és una caracterització incorrecta. Encara que certs restaurants i chefs exploten aquest fenomen, perquè creen esdeveniments falsament 
exclusius o inclouen productes amb poca rellevància gastronòmica (com les làmines d'or) a la cuina per a disparar artificialment els preus, la realitat és que, en general, els preus dels restaurants d'avantguarda no estan pas sobredimensionats (Domene, 2013; Christensen i Pedersen, 2011). La raó central dels alts preus està en la necessitat d'un alt nombre de personal altament qualificat per a atendre relativament pocs clients. En alguns llocs el nombre de persones a la cuina pot ser superior al de persones dinant. De fet, un restaurant com El Bulli era deficitari; d'on treien realment diners en Ferran Adrià i el seu equip era en esdeveniments associats, conferències, tallers, etc. (De Solier, 2010; Domene, 2013). Com va dir Carme Ruscalleda en una entrevista: «un menú degustació no està sobredimensionat, cobrar un biquini a $7 €$, sí» (Sarrias, 2019).

Pel que fa a l'objecció que la cuina d'avantguarda no és més que una forma de gallejar, podem respondre que l'associació de capital social a pràctiques estètiques i culturals no és en absolut una cosa exclusiva de la cuina: assistir a subhastes d'objectes artístics, tenir un seient preferent en un teatre d'òpera o adquirir obres d'art en una galeria són exemples clars d'exhibició de capital social, però això no impedeix pas que les arts visuals o l'òpera s'estudiïn de forma sistemàtica per part de les humanitats. També cal observar que davant d'aquests usuaris que clarament utilitzen els restaurants amb tres estrelles Michelin per exhibir el seu capital social, hi ha un grup, cada cop més nombrós, amb capacitat adquisitiva mitjana que se sent atret per les experiències gastronòmiques sense cap interès de pretendre ser d'un estatus superior (Opazo, 2016). Un fenomen similar podem observar-lo a Bayreuth, on trobarem al mateix teatre persones d'alt poder adquisitiu que van allà simplement a mostrar-se, al costat de fans irredempts de Wagner que potser han estalviat durant mesos per poder gaudir d'El Crepuscle dels Déus. Certament, l'associació del capital social a la gastronomia d'avantguarda s'ha d'estudiar, però no podem limitar a aquest aspecte tota la conceptualització de la gastronomia.
Una part ben rellevant d'aquesta exclusivitat de la gastronomia deriva de la manca de mecanismes de reproductibilitat de l'experiència gastronòmica. Fins l'aparició de les tecnologies de reproducció del so al segle $\mathrm{xx}$, gaudir de la música clàssica era clarament una experiència minoritària. Cal també distingir entre «elitista» $\dot{i}$ «minoritari». A la immensa majoria de la humanitat no sembla que li agradi la música dodecafònica de Schönberg o Alban Berg; cal tenir uns coneixements ben desenvolupats de teoria musical per gaudir-ne, però no diríem que és una música elitista, sinó per a minories (Vilar, 2018).

Finalment, observem que si s'ha donat tanta importància als restaurants d'avantguarda és un cop més per la ignorància manifesta del fet gastronòmic en si mateix. Les humanitats es comencen a interessar per la gastronomia quan aquesta s'artifica i cognifica (Vilar, 2018; Vilar i Jaques, 2010) i recorda més a les arts visuals. Però no cal situar-nos en una cuina d'avantguarda per estudiar la gastronomia com a acte creatiu.

\section{ANÀLISI ENACTIVISTA DELS PROCESSOS CREATIUS EN GASTRONOMIA MOLECULAR}

Aquesta secció és el resultat de la meva participació en el projecte Sapiens (originalment anomenat «Decoding») dins d'El Bulli Lab i de la descripció que es fa dels resultats de la metodologia a Adrià i Pinto (2015). Descric per tant aquí els resultats rellevants del projecte en aquesta època, sense entrar en resultats posteriors del projecte Sapiens. Aquells interessats poden consultar el següent interactiu, desenvolupat per Ferran Adrià i el diari Ara (https://interactius.ara. cat/sapiens/es).

Una de les meves tasques dins d'aquest projecte era establir models cognitius rellevants de caire enactivista per entendre els processos creatius en la gastronomia molecular. En aquest article reviso com una perspectiva enactivista ajuda a comprendre millor els processos creatius en El Bulli i a traslladar-los a altres entorns. 


\section{Què és un model cognitiu enactivista?}

Per «enactivisme» entenem una forma de comprendre les ciències cognitives allunyada de models computacionals o representacionals, on la cognició és un procés dinàmic en el que subjecte, cos i entorn interactuen contínuament creant models cognitius que no podem simplement situar al cervell, sinó que són resultat d'aquesta continua enacció entre ment, cos i entorn (Thompson, 2010; Noë, 2015).

Així, un model cognitiu enactivista funciona com un sistema de ment estesa on el procés cognitiu per resoldre un problema no és un mer resultat d'una computació d'un cervell, sinó que el procés d'anàlisi s'estén a l'entorn.

Hutchins (1995) posa un exemple molt senzill per a entendre aquesta idea: una cua en un forn per a atendre a diverses persones. Els clients van ubicant-se en la cua d'un forn. Amb la cua saben quan els tocarà, i ells poden fer càlculs i decidir si els ve de gust esperar o no. De la mateixa forma, la persona darrere el taulell pot fer-se una idea de qui és el següent que ha d'atendre. Observem com el sistema confia en l'estructura espacial específica de la cua per a fer una petita cognició i establir a qui li toca en un moment determinat. Aquest procés cognitiu no es basa únicament en la ment de la persona responsable del forn, ni tan sols en els esforços cognitius dels usuaris, sinó que sorgeix de forma natural a partir de la interacció de les ments i els cossos del forner i dels clients en un espai organitzat físicament d'una forma concreta.

Els models cognitius enactivistes són molt recents. L'enactivisme -o tercera generació de les ciències cognitives - arrenca amb la publicació de The Embodied Mind l'any 1991. Només recentment ha adquirit suficient popularitat dins les humanitats.

Aquest fet és clau per entendre el desinterès per la gastronomia que hem comentat en el punt 3. Des d'una perspectiva cognitiva clàssica centrada en un cervell que aprén de manera autònoma i on el context és irrellevant, és molt difícil entendre la cuina, ja que es tracta d'una activitat fortament depenent del context i de la interacció entre individus.

És difícil entendre com funciona realment de manera fenomènica la gastronomia des d'un model cartesià. Històricament, la idea era partir del cervell com a màquina processadora de gustos i reduir així el plaer gastronòmic a una sèrie de computacions.

Tanmateix, no hi ha cap necessitat de reduir l'experiència fenomènica de la gastronomia al sentit del gust. Clarament, les sensacions gustatives que es poden generar en degustar alguna cosa -un suc de taronja- no es poden limitar a una combinació de dolç, salat, amarg, àcid i umami. Si fos així, podriem crear qualsevol sabor possible combinant en un perol sal, sucre, suc d'aranja, vinagre i salsa de soja, la qual cosa és un fet clarament absurd.

Tot i així aquesta és la imatge que es té del gust des d'unes neurociències reduccionistes. Així, tenim el famós estudi de Morrot et al. (2001), en el qual uns sommeliers van ser enganyats i no s'adonaren que un suposat vi negre que els havien donat a tastar en realitat era un vi blanc amb un colorant insípid per semblar negre. Molts comentaristes van veure aquí una «sokalització» de la gastronomia, ja que es demostrava que els suposats experts en vi no tenien ni idea. Però el problema aquí no era el coneixement dels experts, sinó considerar que un sommelier és una mena de detector de molècules químiques, quan en realitat el que fa aquesta persona és fruir d'una experiència fenomènica multisensorial, en què gust, aroma i vista treballen conjuntament en un entorn concret que dona sentit al procés de forma global. El mateix fenomen explicaria per què les persones troben més bo un vi que s'ha dit que és més car que un que és més barat, encara que les dues ampolles continguin el mateix vi.

Des de l'enactivisme podem comprendre aquesta confusió resultada de cercar essències a partir de les paraules que emprem i del nostre desig de fer equivalents l'experiència «gustativa» al sentit del gust tal i com el processen els receptors químics de 
la llengua (Noë, 2015). De fet, una experiència gustativa és una experiència multisensorial que inclou també el sentit de l'olfacte i el tacte («sabors» com picant $\mathrm{o}$ astringent són resultat del sentit del tacte de la llengua i no dels receptors químics del gust). També cal incloure el sentit de la vista com a central (aquest sentit és un guia bàsic en tota experiència gustativa). Més secundari però també rellevant és el sentit de la oïda, que té un paper clau en qüestions com el menjar «cruixent».

De fet, el treball de degustació que fem amb la boca és el resultat del treball conjunt de gust, olfacte i tacte, de manera que és una confusió conceptual intencionada reduir l'experiència gastronòmica als detectors de substàncies químiques de la llengua.

És també molt significatiu que al segle xxI encara no tinguem estipulat un vocabulari ben definit dels diferents tipus d'aromes o de sensacions tàctils, per exemple, ni una classificació completa de tipus d'aromes. Actualment els investigadors treballen amb classificacions que venen del món de la perfumeria, que no són ni consistents ni sistemàtiques.

Ferran Adrià és el xef responsable d'haver transformat radicalment la gastronomia durant l'últim mig segle. Motivat sempre per la recerca cap a la innovació, el seu lema i el de l'equip creatiu durant els anys d'activitat del seu restaurant El Bulli ha estat sempre centrar-se en un «retorn a la creació» (Adrià, 2015). Organitzats amb els principis i motius d'un laboratori de recerca científica, l'observació, l'experimentació, la investigació, la formulació d'hipòtesi i la creació de models i tècniques han estat ingredients bàsics per a revisar i qüestionar la disciplina pròpia de la gastronomia, de manera que puguin impulsar constantment el canvi i la millora. Preguntem qualsevol xef reconegut internacionalment sobre el tema i ràpidament reconeixerà el seu deute $\mathrm{amb}$ Ferran Adrià (Opazo, 2012; 2016).

Així, cal evitar entendre la gastronomia molecular, i especialment el projecte d'El Bulli, com una manera de tractar la cuina com a objecte i com a ciència, en què la inspiració i la intuïció ja no són possibles, segons podem veure en les crítiques estàndard del projecte de la gastronomia molecular (tal com les recopilen per exemple Cousins et al., 2010; Hegarty i Antun, 2010). Aquesta forma d'entendre la gastronomia és en realitat un procés tan creatiu com altres formes de cuina; l'ús de ciència i tecnologia no la converteix en un procés mecànic, sinó que és en realitat un element més per a facilitar la creació i la innovació.

Un cop tancat El Bulli, Ferran Adrià va decidir desenvolupar una recerca sistemàtica per establir què és la creativitat i desenvolupar un mètode creatiu que permetés facilitar la innovació i la creació en qualsevol disciplina. Originalment el projecte rebia el nom de «Decoding» i estava pensat com una reconstrucció formal dels processos i mecanismes creatius de diferents disciplines. Tindria una òbvia dedicació a la cuina, però examinaria igualment altres disciplines per tal d'establir quins paràmetres eren universals i quins específics de cada disciplina. Així, hi hauria un decoding de la creació de receptes, un decoding de la decoració d'interiors d'un restaurant i un decoding de cocktails, però també un decoding de la dansa contemporània i un decoding de l'administració d'empreses. Un temps després l'equip d'El Bulli Lab va decidir canviar el nom del projecte a Sapiens, però la idea bàsica de formular una mena d'Aufbau (Carnap, 1928) dels processos creatius ha continuat.

El projecte arrencava de les constatacions que Ferran Adrià havia fet analitzant els seus propis processos creatius. Des dels inicis d'El Bulli, Adrià i el seu equip han anat recollint i catalogant els diferents processos i estructures creatives que han desenvolupat al llarg dels anys: cartes, fitxes de producte, esborranys de plats, bases de dades de proves, receptes que no van funcionar, etc.

La forma de treballar de l'equip d'El Bulli s'entén fàcilment des d'una perspectiva enactivista. Una d'aquestes constatacions és que contra la idea romàntica d'un geni creatiu que bàsicament inventa el que 
vol, la creativitat en cuina està molt condicionada per les propietats físiques, químiques i organolèptiques dels materials amb què treballa, les tecnologies que es tenen a l'abast i la gestió del temps i dels equips.

Això li permet a Adrià establir uns paràmetres bàsics per desenvolupar el seu procés de decodificació o «Sapiens». Independentment de si un busca innovar en cuina, en videoart o en el disseny d'automòbils de carreres, hi ha una sèrie de condicionants genèrics que poden facilitar o bé dificultar el procés creatiu. Tanmateix, aquests mateixos condicionants són els que fan possible la creativitat. Si fos possible donar qualsevol textura i sabor a qualsevol material amb una determinada tecnologia, la creativitat en la gastronomia es limitaria a desitjar quina mena de resultat busquem i llavors cercar quines tècniques concretes farien possible aquest resultat. El fet que això no sigui possible fa que calguin individus creatius capaços de recopilar la seva experiència prèvia i cercar noves formes d'innovar.

Del model Sapiens i dels patrons de recerca del model enactivista es deriva també que els processos creatius en cuina siguin distribuïts; no hi ha un geni creatiu responsable definitiu del plat, com la premsa genèrica es deleix per presentar, sinó un esforç d'equip, que inclou cuiners, stageurs, productors, distribuïdors i comensals. A més, cap procés creatiu es dona en un buit, ni tan sols en un indret tan reclòs com la cuina, de manera que hem d'incloure d'una banda altres disciplines que poden inspirar el procés creatiu i d'altra, els condicionaments històrics i del entorn.

Veiem primer els condicionaments històrics: el ja esmentat foodpairing, el fet que certes combinacions d'aliments funcionin en cuina i altres no, és resultat d'un procés històric. Seria un error pensar que el foodpairing és quelcom inscrit en les nostres neurones. De nou, es tracta d'un procés enactivista on ment, cos i entorn treballen de forma conjunta.

El cànon culinari sorgeix de l'adopció de certes receptes com a estándar, resultat de la combinació de diferents factors climàtics, tecnològics, socials i fins i tot religiosos. Si creiem que ceba, albergínia, pebrot i tomàquet són una bona combinació no és simplement degut a la seva compatibilitat molecular sinó a segles d'història que els han mantingut junts. La decisió d'anomenar Sapiens la seva metodologia és un homenatge al llibre de Harari (Harari, 2014) i per tant un reconeixement del gran pes que té la història en els processos creatius de la gastronomia.

La cuina d'avantguarda, anomenem-la «tecnoemocional»o «molecular», té en els processos creatius una forta influència interdisciplinar. El Roner o el Rotaval dels germans Roca són resultat d'aplicar principis i tecnologies de la física i la química a la cuina; només podem entendre la inclusió de Ferran Adrià a la biennal d'art Documenta (Todolí i Hamilton, 2009) pels homenatges que Ferran Adrià fa a la cultura visual del segle xx amb plats com els «Molls Gaudí» (Adrià, 1998).

Molt important també en el model Sapiens és assegurar mecanismes facilitadors de la creativitat, per exemple, que el chef tingui temps lliure per a ser creatiu. Així s'explica la trencadora decisió de Ferran Adrià de tenir El Bulli tancat durant sis mesos i oferir només sopars. D'aquesta manera l'equip d'El Bulli disposava de temps suficient per a fer noves proves i experiments, cercar inspiració en altres llocs, viatjar per trobar noves tècniques, idees, productes, etc. També és clau la logística del restaurant perquè cadascuna de les fases del manteniment del restaurant fluís de manera natural i sense friccions i així assegurar que mantenir el restaurant obert no generava càrrega cognitiva extra i poder dedicar la major part del temps a crear.

Aquest és, segurament, l'element més important de la metodologia Sapiens: garantir la màxima eficiència dels processos productius i creatius i analitzar al màxim els detalls concrets d'aquests processos per a assegurar la fluïdesa màxima (Maes, 1994). D'aquests estudis micro deriva un resultat clau: cada disciplina té els seus mecanismes creatius i no es poden trasplantar de manera automàtica a una altra disciplina. Es necessita una reelaboració detallada, on es reconstrueixin les con- 
nexions concretes entre objectes, productes i mètodes de cada disciplina. Així, encara que superficialment un pugui creure que els mecanismes creatius del disseny gràfic i la cuina són similars -com decidir la idoneïtat de certes combinacions- la realitat és que si volem entendre la relació entre el foodpairing i el colorpairing hem d'analitzar i sistematitzar els mecanismes -i les bases psicològiques i històriques concretes- que fan que dos sabors o dos colors combinin bé o no i que siguin en bona part independents, malgrat que hi hagi connexions.

De l'anàlisi de Sapiens resulta també que les limitacions no són enemigues de la creativitat, ans al contrari: la creativitat sorgeix per a respondre a certes limitacions que la història o l'entorn ens plantegen. Només si entenem aquestes limitacions podrem plantejar-nos respostes realment creatives $i$, seguint les idees de Cross, visualitzar aquests wicked problems i decidir fins a quin punt volem qüestionar aquestes limitacions. En els repertoris de la cuina clàssica és molt difícil trobar plats que siguin totalment negres. Aquesta inexistència és resultat de quelcom intrínsec en la natura d'aquests aliments? És un fet psicològic transcultural? O és resultat de processos històrics i socials? Un cop entenguem aquest fenomen podrem plantejar-nos si té sentit fer un plat on tots els ingredients siguin negres i de quina manera s'ha de produir. Aquesta decisió generarà al seu torn altres problemes: haig de servir aquesta elaboració en un plat també negre? En quin moment del menú s'ha de servir? Calen altres acompanyaments sensorials?

En aquest procés intervindran diferents processos cognitius enactivistes que llistem breument aquí en forma de taula, fent una comparativa entre cuina tradicional i molecular (Taula 1).

\section{CONCLUSIONS}

Malgrat que superficialment sembli que hi ha una gran separació entre la cuina tradicional i la gastronomia molecular, en realitat la gastronomia molecular no és més que un intent de sistematització a partir de les ciències experimentals i els models cognitius de les intuïcions bàsiques dels cuiners.

Taula 1

\begin{tabular}{|l|l|l|}
\hline \multicolumn{1}{|c|}{ Problema } & \multicolumn{1}{|c|}{ Model tradicional } & \multicolumn{1}{c|}{ Gastronomia molecular } \\
\hline Enregistrar recepta & $\begin{array}{l}\text { Textos ambigus basats en } \\
\text { experiència compartida }\end{array}$ & $\begin{array}{l}\text { Redacció científica d'una recepta, quantitats } \\
\text { exactes, etc. }\end{array}$ \\
\hline $\begin{array}{l}\text { Decidir combinacions } \\
\text { correctes }\end{array}$ & $\begin{array}{l}\text { Coneixement intuïtiu basat } \\
\text { en tradició compartida }\end{array}$ & $\begin{array}{l}\text { Coneixement històric i biològic sistemàtic que } \\
\text { expliqui aquestes intuïcions }\end{array}$ \\
\hline Innovar en tècniques & $\begin{array}{l}\text { Ús intuïtiu de nous estris } \\
\text { (olla de pressió, microones, } \\
\text { etc.) }\end{array}$ & $\begin{array}{l}\text { Ús fonamentat en ciència bàsica de les capacitats } \\
\text { de nous estris }\end{array}$ \\
\hline Innovar en tecnologies & Assaig i error & $\begin{array}{l}\text { Petició a enginyers -basada en coneixements } \\
\text { científics- per a la creació de noves tecnologies } \\
\text { (Rotaval, Roner) }\end{array}$ \\
\hline $\begin{array}{l}\text { Innovar en combina- } \\
\text { cions }\end{array}$ & Assaig i error & $\begin{array}{l}\text { Combinar coneixements químics, neurològics i } \\
\text { històrics (foodpairing) }\end{array}$ \\
\hline
\end{tabular}


Per tant, s'ha d'entendre la gastronomia des d'una perspectiva enactivista, on ment, cos i entorn interactuen contínuament en un procés de retroalimentació. És també un sistema multisensorial on les expectatives i els coneixements de comensals i cuiners tenen un paper clau.

El projecte «Sapiens» d'El Bulli Lab és un exemple perfecte d'aquest tipus de recerca, que parteix de la idiosincràsia de la cuina per establir quins mecanismes són genèrics i traslladables a altres disciplines i poden considerar-se mecanismes generals de creativitat.

I aquest és, de fet, un dels resultats centrals d'aquesta metodologia: establir que la creativitat és la resposta a certes limitacions, però que aquestes limitacions són les que fan possible finalment la creativitat. Com el colom kantià que espera volar millor en un espai sense aire, però descobreix que aquesta suposada limitació és en realitat condició per al vol: les limitacions que ens imposa cada disciplina són les que fan la creativitat possible.

Aquestes limitacions difereixen en cada disciplina, tant per factors inherents als processos de producció, com per allò que històricament s'ha establert com a resultat acceptable o no.

Així, un estudi de la creativitat no pot esperar produir mecanismes genèrics que garanteixin la creativitat en qualsevol context. És a dir, no podem mecanitzar la creativitat com a procés genèric ni esperar tenir un model formal global de com és un procés creatiu. El que sí que podem sistematitzar de manera global és quins mecanismes faciliten o dificulten la creativitat quan es guarda temps per dedicar-lo al procés creatiu i quan es retira càrrega cognitiva en altres processos.

Podem contemplar Sapiens com un exercici wittgenstenià de mostrar que el terme «creativitat» en realitat s'utilitza en molts jocs de llenguatge diferents i que no té gaire sentit trobar unes lleis globals que el defineixin independentment de la disciplina. La veritable recerca entorn de la creativitat i la innovació no ha de cercar establir unes lleis universals i immutables del procés creatiu, sinó uns protocols genèrics que facilitin a la persona creativa disposar de temps i capacitat mental per tal de poder-se dedicar al procés creatiu sense entrebancs.

En paral-lel, Sapiens mostra com el procés creatiu no és resultat del geni individual de una persona beneïda per les muses, sinó el resultat d'un procés en equip, d'una creació col-lectiva, distribuïda (Hutchins, 1995), en què l'agent últim del procés creatiu és un equip d'individus que treballen de forma coordinada amb l'ajuda de diferents estris tecnològics i que són codependents de factors ambientals i culturals.

\section{REFERÈNCIES BIBLIOGRÀFIQUES}

Accum, F. C. (1821). Culinary Chemistry, Exhibiting the Scientific Principles of Cookery. Londres: R. Ackermann.

Adrià, F. (1998). Los Secretos de El Bulli: recetas, técnicas y reflexiones. Altaya.

Adrià, F. i Pinto, J. M. (2015). Sapiens: Una metodología para entender la gastronomía. Temes de disseny, 31, $10-21$.

Ahn, Y. Y., Ahnert, S. E., Bagrow, J. P. i Barabási, A. L. (2011). Flavor network and the principles of food pairing. Nature Scientific Reports, 1.

Appert, N. (1810). L'art de conserver pendant plusieurs années toutes les substances animales et végétales. París: Chez Patris. Arenós, P. i Jardí, E. (1999). Los genios del fuego: quiénes son, cómo crean y qué cocinan 10 chefs de vanguardia. Barcelona: Ediciones Península.

Brillat-Savarin, J. A. (1828). The Physiology of Taste. Or Meditations on Transcendental Gastronomy. Washington, DC: Counterpoint Press. 
Carnap, R. (1928). Der logische Aufbau der Welt. Berlín: Schlachtensee.

Celant G. (2015). Arts and Design. Rituals since 1851. Milà: Electa.

Castells, P. i Perelló, J. (2010). Materia Condensada. Cocinar Ciencia. En Cocinar ciencia. Materia condensada. Barcelona: Actar.

Christensen, B. T. i Pedersen, J. S. (2011). Evaluative Practices in the Culinary Field - a Case of Restaurant Rankings. Copenhagen Business School, 2-20.

Cousins, J., O'Gorman, K. i Stierand, M. (2010). Molecular gastronomy: cuisine innovation or modern day alchemy? International Journal of Contemporary Hospitality Management.

Cross, N. (2007). Creativity: Flow and the Psychology of Discovery and Invention. Nova York: Harper \& Collins.

de Redacció, T. C. (2017). Terminàlia parla amb... Carme Ruscalleda i Serra, primera xef catalana que aconsegueix set estrelles Michelin. Terminàlia, 38-41.

De Solier, I. (2010). Liquid nitrogen pistachios: Molecular gastronomy, El Bulli and foodies. European Journal of Cultural Studies, 13(2), 155-170.

Domene, M. (2013). El Bulli: Contemporary intersections between food, science, art and late capitalism. Barcelona Investigación Arte Creación, 1(1), 100-126.

Dorst K. (2006). Design Problems and Design Paradoxes. Design Issues, 22(2), 4-12.

Eloire, F. (2018). The Bourdieusian conception of social capital: a methodological reflection and application. Forum for Social Economics, 47(3-4), 322-341.

Fundación Alícia i elBullitaller (2006). Léxico científico gastronómico. Barcelona: Planeta.

Harari, Y. N. (2014). Sapiens. De animales a dioses: Una breve historia de la humanidad. Debate.

Hawkes, C. H. i Doty, R. L. (2009). The neurology of olfaction. Cambridge University Press.

Hegarty, J. i Antun, J. (2010). Is the Chemical Chef Dividing Culinary Arts and Gastronomy? Journal of Culinary Science and Technology, 8(2-3), 73-82.

Hutchins, E. (1995). Cognition in the Wild. MIT press.

Keast, R. S. i Costanzo, A. (2015). Is fat the sixth taste primary? Evidence and implications. Flavour, $4(1), 5$.

Korsmeyer, C. (2002). Making sense of taste: food and philosophy. Cornell University Press.

Kurti, N. (1980). The physicist in the kitchen. New Sci, 88, 786-789.

López-Alt, J. K. (2015). The Food Lab: Better Home Cooking Through Science. W. W. Norton \& Company.

Lyman, B. (2012). A psychology of food: More than a matter of taste. Springer Science \& Business Media.

Maes, P. (1994). Agents that reduce work and information overload. Communications of the ACM, 37(7), 30-40.

McGee, H. (1984). On food and cooking: the science and lore of the kitchen. Nova York: Simon and Schuster.

Morrot, G., Brochet, F. i Dubourdieu, D. (2001). The Color of Odors. Brain and Language.

Myhrvold, N. (2011). Modernist cuisine. Colònia, Alemanya: Taschen.

Noë, A. (2015). Strange tools: Art and human nature. Hill and Wang.

Opazo, M. P. (2012). Discourse as driver of innovation in contemporary haute cuisine: The case of El Bulli restaurant. International Journal of Gastronomy and Food Science, 1(2), 82-89.

Opazo, M. P. (2016). Appetite for innovation: Creativity and change at El Bulli. Columbia University Press.

Platón (1989). Diàlegs, vol. X: La república. Fundació Bernat Metge.

Robberechts, D., Lahousse, B., Coucquyt, P. i Langenbick, J. (2015). 14/165,455. U.S. Patent Application.

Sarrias, T. (2019). Punts de Vista. Entrevista a Carme Ruscalleda [vídeo]. RTVE. https://www.rtve.es/alacarta/videos/ punts-de-vista/punts-vista-entrevista-carme-ruscalleda/5480837/

Simon, H. A. (1996). The sciences of the artificial. Cambridge: MIT press.

Stewart, J. E., Feinle-Bisset, C., Golding, M., Delahunty, C., Clifton, P. M. i Keast, R. S. (2010). Oral sensitivity to fatty acids, food consumption and BMI in human subjects. British journal of nutrition, 104(1), 145-152.

This, H. (1999). Nicholas Kurti, one of the founding fathers of molecular gastronomy. Acta Physica Hungarica New Series-Heavy Ion Physics, 10(1), 21-28.

This, H. (2002). Casseroles et éprouvettes. París: Berlin pour la science.

Thompson, E. (2010). Mind in life. Harvard University Press. 
Todolí, V. i Hamilton, R. (ed.) (2009). Menjar per pensar, pensar per menjar. Barcelona: Actar.

Vilar, G . (2018). La cognificació de l'art. Quaderns de filosofia, 5(2), 11-28.

Vilar, G. i Jacques, J. (2010). Feeding thought: por una filosofía de la gastronomía y la cocina Disturbis, 12, 1-30.

\section{NOTA BIOGRÀFICA}

David Casacuberta és doctor en Filosofia per la Universitat Autònoma de Barcelona. Actualment és professor agregat en aquesta universitat. Les seves línies de recerca són els impactes socials i cognitius de les tecnologies digitals, especialment les qüestions ètiques i epistèmiques que sorgeixen en aplicar aquestes tecnologies a les ciències biomèdiques. 